
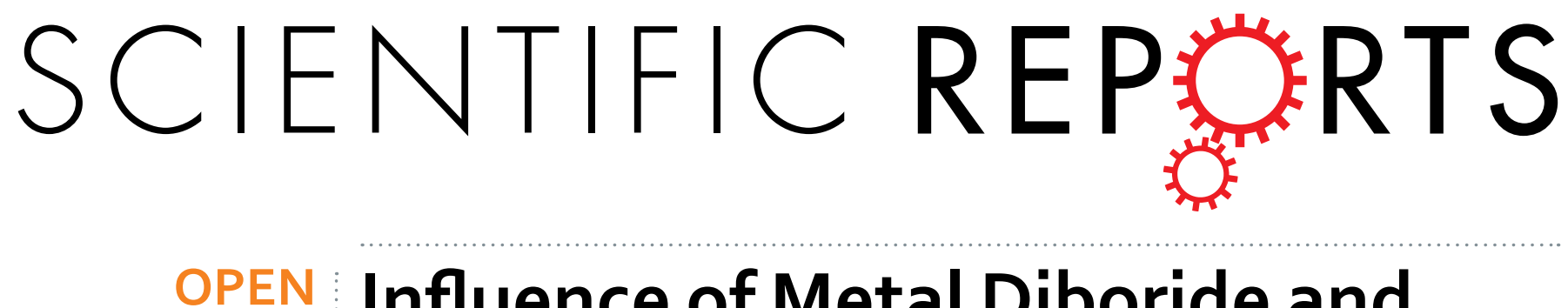

\title{
Influence of Metal Diboride and
} $\mathrm{Dy}_{2} \mathrm{O}_{3}$ Additions on Microstructure
and Properties of $\mathrm{MgB}_{2}$ Fabricated

Received: 30 March 2016

Accepted: 13 June 2016

Published: 13 July 2016 at High Temperatures and under Pressure

\section{Y. Yang, M. D. Sumption \& E. W. Collings}

High temperatures and under pressure (HTP) processing has been used to study the effects of chemical doping in $\mathrm{MgB}_{2} . \mathrm{ZrB}_{2}, \mathrm{TiB}_{2}$ and $\mathrm{NbB}_{2}$ were selected as additives since, like $\mathrm{MgB}_{2}$, they have an $\mathrm{AlB}_{2}$ type structure and similar lattice parameters. $\mathrm{Dy}_{2} \mathrm{O}_{3}$ was selected as it has been reported to generate nanoscale, secondary intragrain phases in $\mathrm{MgB}_{2}$. While $\mathrm{C}$ is known to enter the B-sublattice readily, attempts to dope $\mathrm{Zr}$ and other elements onto the $\mathrm{Mg}$ site have been less successful due to slow bulk diffusion, low solubility in $\mathrm{MgB}_{2}$, or both. We have used high-temperature, solid-state sintering $\left(1500^{\circ} \mathrm{C}\right)$, as well as excursions through the peritectic temperature (up to $1700^{\circ} \mathrm{C}$ ), to investigate both of these limitations. Bulk MgB samples doped with $\mathrm{MB}_{2}(\mathrm{M}=\mathrm{Zr}$, Ti and $\mathrm{Nb})$ and $\mathrm{Dy}_{2} \mathrm{O}_{3}$ additions were synthesized and then characterized. Lattice distortion and high densities of crystal defects were observed in the $\mathrm{MgB}_{2}$ grains around nano-sized $\mathrm{MB}_{2}$ inclusions, this highly defected band contributed to a large increase in $B_{c 2}$ but was not large enough to increase the irreversibility field. In contrast, distributed intragrain precipitates were formed by $\mathrm{Dy}_{2} \mathrm{O}_{3}$ additions which did not change the lattice parameters, $T_{c l} T_{c}$ distribution or $B_{c 2}$ of $\mathrm{MgB}_{2}$, but modified the flux pinning.

Extensive efforts have been expended in doping $\mathrm{MgB}_{2}$ to enhance its superconductive properties, particularly its upper critical field, $B_{c 2}$. The substitution of $\mathrm{C}$ for $\mathrm{B}$ has been shown to significantly increase $\mathrm{MgB}_{2}$ 's $B_{c 2}$ beyond that of the unalloyed sample ${ }^{1-6}$. Unfortunately, $C$ doping is successful only at low temperatures $(<20 \mathrm{~K})$ since it reduces $T_{c}$ and increases electron impurity scattering only in the $\sigma$ band, leaving the high temperature $(>20 \mathrm{~K})$ $B_{c 2}$ unchanged or even reduced. In order to enhance the $B_{c 2}$ of $\mathrm{MgB}_{2}$ in the higher temperature regime, many attempts have been made to find effective dopants for $\mathrm{Mg}$-site substitution to increase electron impurity scattering in both the $\sigma$ band and the $\pi$ band $^{7,8}$, but without much success in terms of improved properties. Although the substitution of $\mathrm{Al}$ for $\mathrm{Mg}$ has been demonstrated, it was found to reduce $B_{c 2}{ }^{9,10}$.

Further studies focusing on the $\mathrm{AlB}_{2}$-like metal diborides $\mathrm{ZrB}_{2}, \mathrm{TiB}_{2}$ and $\mathrm{NbB}_{2}$, (e.g. refs 11-16) yielded contradictory results. Feng et al. ${ }^{11,12}$ reported an enhancement in $B_{c 2}$ in response to $10 \mathrm{~mol} \% \mathrm{Zr}$ doping; Bhatia et al. ${ }^{13}$ observed a significant increase in $B_{c 2}$ (from $20.5 \mathrm{~T}$ to $28.6 \mathrm{~T}$ at $4.2 \mathrm{~K}$ ) after adding $7.5 \mathrm{~mol} \% \mathrm{ZrB}_{2}$ to $\mathrm{MgB}_{2}$ bulks. On the other hand, Zhang et al. ${ }^{14}$ reported no $B_{c 2}$ enhancement in $\mathrm{ZrB}_{2}$ doped $\mathrm{MgB}_{2}$ tapes. In any case, while $B_{c 2}$ enhancements have been noted by various researchers working with $\mathrm{MgB}_{2}$ PIT or powder type processes, no one has reported enhanced transport current, suggesting that the effect may be in a surface layer. The one effort to date which has clearly injected $\mathrm{Zr}$ deeply into the grain, resulting in a pulsed laser deposition (PLD) synthesized $\mathrm{ZrB}_{2}$-doped $\mathrm{MgB}_{2}$ thin film ${ }^{15,16}$, showed a much stronger response to the presence of $\mathrm{Zr}$, and in this case a decrease of $T_{c}$ and $B_{c 2}$ with increasing $\mathrm{Zr}$ content. These various observations give rise to the question: what is the actual influence of $\mathrm{Zr}$ doping in $\mathrm{MgB}_{2}$ ? The possible roles of $\mathrm{Zr}$ in $\mathrm{MgB}_{2}$ can be summarized in terms of: 1) extrinsic effects, such as modified intergranular connectivity and reduced grain size $\left.{ }^{11,12} ; 2\right)$ intrinsic effects, such as an influence on $B_{c 2}$ of $\mathrm{Zr}$ substitution for $\mathrm{Mg}^{13-16}$, or increased flux pinning by a distribution of nano-sized $\mathrm{ZrB}{ }_{2} / \mathrm{Zr}$

Center for Superconducting and Magnetic Materials, Department of Materials Science and Engineering, the Ohio State University, Columbus, OH, USA. Correspondence and requests for materials should be addressed to Y.Y. (email: yang.1444@osu.edu) or M.D.S. (email: sumption.3@osu.edu) 
(a)

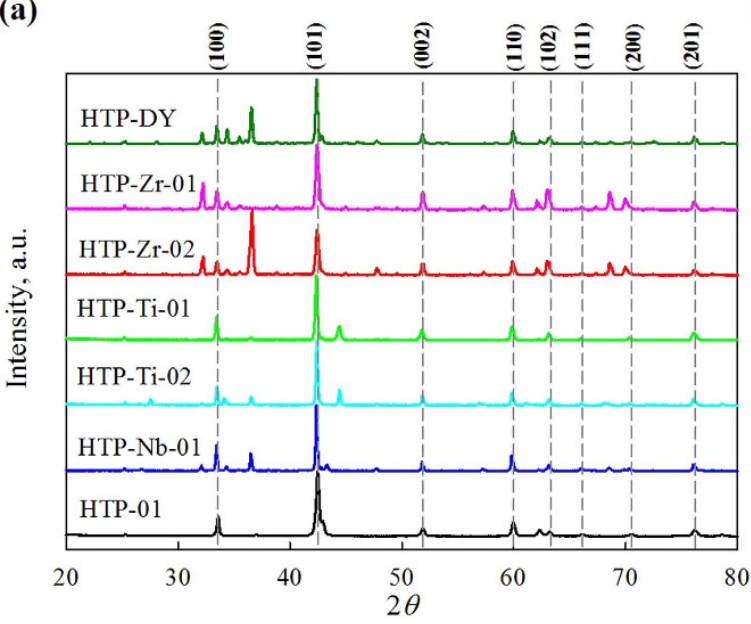

(b)

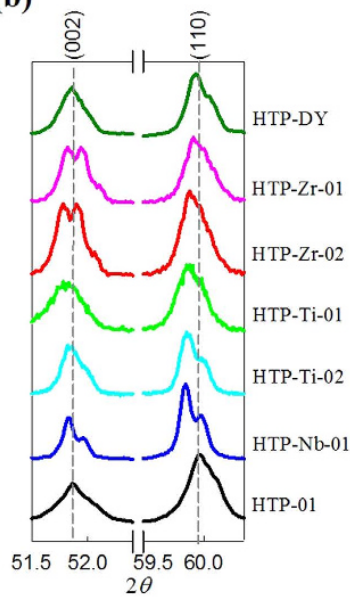

Figure 1. (a) X-ray diffraction characterization of undoped $\mathrm{MgB}_{2}$ sample HTP-01, and all theMB ${ }_{2}$ doped samples; (b) Peaks (110) and (002), as these two peaks are directly related to lattice parameter $a$ and $c$, respectively. Note for the $\mathrm{MB}_{2}$ doped samples, small peak shifting and $\mathrm{MB}_{2}$ peaks are observed, while no peak shifting is observed in the $\mathrm{Dy}_{2} \mathrm{O}_{3}$ doped sample.

precipitates ${ }^{14}$. On the other hand, incomplete microscopic evidence of $\mathrm{Zr}$ substitution for $\mathrm{Mg}$ has been provided, at least for materials made by equilibrium processes (contrasting to the non-equilibrium processing of the films of $\left.{ }^{15,16}\right)$. Therefore further study on the limits of $\mathrm{Zr}$ doping was deemed necessary.

There are many roadblocks to clarifying the true role of chemical doping in $\mathrm{MgB}_{2}$. Chief among them is that homogeneous doping is very hard to achieve. Traditional powder synthesis is generally performed at $600-1000^{\circ} \mathrm{C}-$ too low to form homogeneously doped samples. To overcome this problem a high temperature under pressure (HTP) route (see below) was developed to explore solubility limits of dopant species in $\mathrm{MgB}_{2}$ and maximize diffusion during reaction. $\mathrm{MgB}_{2}$ bulks synthesized by HTP should have a greater depth of dopant penetration into the $\mathrm{MgB}_{2}$ for any species introduced (if it is soluble) given the increase in diffusion rate at higher temperatures. HTP samples also have large grain size (over $5 \mu \mathrm{m}$ ) making chemical analysis easier. The purpose of the HTP method is to minimize any diffusion limitations so that we can explore the solubility limits of doping, rather than to fabricate $\mathrm{MgB}_{2}$ bulk samples with high $J_{c}$. Also, the use of existing metal diborides $\left(\mathrm{MB}_{2}\right)$ with a structure isomorphous to $\mathrm{MgB}_{2}(\mathrm{P} 6 / \mathrm{mmm})$ as a vector for effective metal element doping is a promising way to investigate possible changes of superconducting properties like $B_{c 2}$ and $T_{c}$. Thus, three sets of $\mathrm{MgB}_{2}$ bulks doped with $\mathrm{ZrB}_{2}$, $\mathrm{TiB}_{2}$ and $\mathrm{NbB}_{2}$ powders were prepared.

Most additions which have been attempted for $\mathrm{MgB}_{2}$ tend to accumulate at the grain boundaries, with the exception of the above-mentioned C-bearing additions. On the other hand, several studies have shown that a very small amount of $\mathrm{Dy}_{2} \mathrm{O}_{3}{ }^{17}$ can form nanosize precipitates within the $\mathrm{MgB}_{2}$ grains and thereby enhance flux pinning without changing $T_{c}$. Thus a $\mathrm{Dy}_{2} \mathrm{O}_{3}$ doped $\mathrm{MgB}_{2}$ bulk was also included in this study for comparison. The changes in microstructure and lattice parameter, as well as the superconducting properties $B_{c 2}, T_{c}$ and flux pinning were studied for all samples and are discussed below.

\section{Results and Discussion}

Influence of $\mathrm{MB}_{2}$ and $\mathrm{Dy}_{2} \mathrm{O}_{3}$ doping on XRD and lattice constants. The X-ray diffraction data for all HTP bulks are presented in Fig. 1 where the Bragg reflections are indexed for only the $\mathrm{MgB}_{2}$ phase for simplicity. $\mathrm{MgO}$ and $\mathrm{Mg}$ were present at some level in all samples ( $\mathrm{MgO}$ was less than about $2 \mathrm{wt} \%$ for samples reacted below the peritectic). $\mathrm{MgB}_{4}$ peaks are also present for samples $\mathrm{HT}$ at $1700^{\circ} \mathrm{C}$. Only a very small peak shift (less than 0.2 degree) at both (110) and (002) was observed in $\mathrm{MB}_{2}$ doped samples while no peak shift was observed for the $\mathrm{Dy}_{2} \mathrm{O}_{3}$ doped sample. Peaks corresponding to $\mathrm{MB}_{\mathrm{x}}$ impurity phases were observed in all $\mathrm{MB}_{2}$ doped samples. The lattice parameters extracted from pseudo-Voigt fitting the $\mathrm{MgB}_{2}$ peak reflections and the calculated lattice parameters by Vegard's law are given in Table 1. For the $\mathrm{Dy}_{2} \mathrm{O}_{3}$ added sample HTP-DY, similar to Chen's report ${ }^{17}$, the lattice parameters $a$ and $c$ did not change with $\mathrm{Dy}_{2} \mathrm{O}_{3}$ addition. Similarly, for the $\mathrm{MB}_{2}$ added samples, even though both lattice parameters $a$ and $c$ were slightly changed, these changes were very small and none of the doped samples obeyed Vegard's law, unlike C-doped $\mathrm{MgB}_{2} \mathrm{HTP}_{\text {bulks }}{ }^{6}$. Therefore it seems that even under HTP processing the metal borides $\left(\mathrm{ZrB}_{2}, \mathrm{TiB}_{2}\right.$ and $\left.\mathrm{NbB}_{2}\right)$ mainly acted as impurity phases and did not form homogeneous solid solutions with $\mathrm{MgB}_{2}$, at least not to an extent detectable by XRD. However, the small changes in lattice parameters suggest that a distortion of the $\mathrm{MgB}_{2}$ lattice was present. Such distortion, caused by strain generated around these dopant impurities (see below) rather than elemental substitution, appears to be the driver for the modified upper critical field $B_{c 2}$ of the doped samples.

Influence of $\mathrm{MB}_{2}$ and $\mathrm{Dy}_{2} \mathrm{O}_{3}$ doping on microstructure - SEM and TEM. The results of back-scatter (BSE) SEM characterization performed on the $\mathrm{ZrB}_{2}$ doped samples are presented in Fig. 2. The microstructures of HTP-Zr- $01\left(1500^{\circ} \mathrm{C}\right.$, below the peritectic temperature $)$ and $\mathrm{HTP}-\mathrm{Zr}-02\left(1700^{\circ} \mathrm{C}\right.$, above the peritectic temperature) are shown in Figs 2(a) and 3(b) (for comparison, the microstructures of the undoped bulk can be found 


\begin{tabular}{|c|c|c|c|c|c|c|c|}
\hline Sample & Dopant:B ratios ${ }^{1}$ & HTs at $10 \mathrm{MPa}$ & $a, \AA$ & $a_{\mathrm{cal}}, \AA^{2}$ & $c \AA$ & $c_{\text {cal }}, \AA$ & MB $_{x}$ Impurities $^{3}$ \\
\hline HTP-01 & - & $1500^{\circ} \mathrm{C}, 30 \mathrm{~min}$ & $3.082(5)$ & - & $3.521(7)$ & - & - \\
\hline HTP-Zr-01 & $\mathrm{ZrB}_{2}: \mathrm{B}=1: 40$ & $1500^{\circ} \mathrm{C}, 30 \mathrm{~min}$ & $3.086(4)$ & 3.085 & $3.530(1)$ & 3.522 & $1 \mathrm{wt} \% \mathrm{ZrB}_{2}$ \\
\hline HTP-Zr-02 & $\mathrm{ZrB}_{2}: \mathrm{B}=1: 19$ & $1700^{\circ} \mathrm{C}, 20 \mathrm{~min}$ & $3.090(2)$ & 3.091 & $3.527(4)$ & 3.522 & $8.6 \mathrm{wt} \% \mathrm{ZrB}_{2}$ \\
\hline HTP-Ti-01 & $\mathrm{TiB}_{2}: \mathrm{B}=1: 40$ & $1500^{\circ} \mathrm{C}, 30 \mathrm{~min}$ & $3.089(3)$ & 3.082 & $3.523(8)$ & 3.516 & $1.7 \mathrm{wt} \% \mathrm{TiB}_{2}$ \\
\hline HTP-Ti-02 & $\mathrm{TiB}_{2}: \mathrm{B}=1: 19$ & $1700^{\circ} \mathrm{C}, 20 \mathrm{~min}$ & $3.085(4)$ & 3.077 & $3.520(2)$ & 3.492 & $11.3 \mathrm{wt} \% \mathrm{TiB}_{2}$ \\
\hline HTP-Nb-01 & $\mathrm{NbB}_{2}: \mathrm{B}=1: 40$ & $1500^{\circ} \mathrm{C}, 30 \mathrm{~min}$ & $3.086(3)$ & 3.084 & $3.517(4)$ & 3.517 & $2.7 \mathrm{wt} \% \mathrm{NbB}_{2}$ \\
\hline HTP-Dy & $\mathrm{Dy}_{2} \mathrm{O}_{3}: \mathrm{B}=1: 800$ & $1700^{\circ} \mathrm{C}, 20 \mathrm{~min}$ & $3.082(9)$ & - & $3.522(5)$ & - & $1.4 \mathrm{wt} \% \mathrm{DyB}_{4}$ \\
\hline
\end{tabular}

Table 1. Doping levels, heat-treatment parameters, lattice parameters and $M B_{x}$ impurity amounts for the $\mathrm{MgB}_{2}$ samples. ${ }^{1}$ These ratios were based on the mole ratios between the dopants and B in the mixtures. ${ }^{2}$ The $a_{c a l}$ and $c_{c a l}$ were the calculated values based on Vegard's law by assuming that all dopants form a homogeneous solid solution with $\mathrm{MgB}_{2} .{ }^{3}$ The $\mathrm{x}$ in $\mathrm{MB}_{\mathrm{x}}$ are 2 in the $\mathrm{MB}_{2}$ doped samples and 4 in the $\mathrm{Dy}_{2} \mathrm{O}_{3}$ doped sample, respectively.

in $^{6,18,19}$ ). Two phases are visible: $\mathrm{MgB}_{2}$ (majority phase, dark grey) and $\mathrm{ZrB}_{2}$ (minority phase, white) in $\mathrm{HTP}-\mathrm{Zr}-01$; while in $\mathrm{HTP}-\mathrm{Zr}-02, \mathrm{Mg}$ and $\mathrm{MgB}_{4}$ phases were present since it experienced (upon cooling) the reaction $M g B_{4}+M g \Rightarrow 2 M g B_{2}$.

Figure 2(c) represents the bright-field (BF) TEM image obtained from a thin foil extracted from HTP-Zr-02 $\left(1700^{\circ} \mathrm{C}\right)$. This foil contains a cross section of several grains. The results from the energy dispersive spectroscopy analysis (EDS) and selected area diffraction (SAD) confirm that these large grains are $\mathrm{MgB}_{2}$. An intragranular crack and dislocation loops are present in one of the grains. Since HTP-Zr-02 was processed above the peritectic, the crack presumably resulted from volume expansion taking place during cooling as the $\mathrm{MgB}_{4}$ converted into $\mathrm{MgB}_{2}$. TEM examination revealed a number of impurity phases in the form of 30-80 nm inclusions around the $\mathrm{MgB}_{2}$ grains, Fig. 2(d). The results of EDS analysis performed on these inclusions are presented in Fig. 2(e). It is clear that these inclusions contain $\mathrm{Zr}$, or possibly $\mathrm{ZrB}_{2}$, which is likely dispersed around the $\mathrm{MgB}_{2}$ grains in the bulk. Compared to other areas inside the $\mathrm{MgB}_{2}$ grains, the regions around these $\mathrm{ZrB}_{2}$ inclusions have much higher contrast under BF condition, which suggests that strain fields were generated around these inclusions and that the $\mathrm{MgB}_{2}$ lattice was distorted locally. This local lattice distortion may be the origin of the slight lattice parameter changes observed by XRD analysis in Section 3.1. Figure 2(f) shows HAADF imaging for one of these nano-size inclusions. Since HAADF imaging is sensitive to variations in the atomic number (Z-contrast), these white inclusions should have a higher average atomic number than $\mathrm{MgB}_{2}$. A STEM-EDS line scan applied using 21 distinct points over $\sim 100 \mathrm{~nm}$ across this inclusion confirmed it was $\mathrm{ZrB}_{2}$. The $\mathrm{Zr}$ signal dropped to zero quickly outside of the inclusion, beyond the $\mathrm{ZrB}_{2} / \mathrm{MgB}_{2}$ interface. The spatial resolution of the STEM-EDS line scans is about $5 \mathrm{~nm}$, thus these observation indicate that $\mathrm{Zr}$ did not notably penetrate into the $\mathrm{MgB}_{2}$ lattice.

Figure 3 shows the BSE images of the $\mathrm{TiB}_{2}$ doped samples, $\mathrm{HTP}-\mathrm{Ti}-01\left(1500^{\circ} \mathrm{C}\right.$, below the peritectic) and HTP-Ti-02 $\left(1700^{\circ} \mathrm{C}\right.$, above the peritectic). Similar to the behavior of $\mathrm{ZrB}_{2}, \mathrm{TiB}_{2}$ mainly acts as an impurity phase (light grey in Fig. 4(a,b)) and is widely distributed. A TEM thin foil containing a cross section of both $\mathrm{TiB}_{2}$ and $\mathrm{MgB}_{2}$ grains was carefully extracted from HTP-Ti-01. A BF image including $\mathrm{MgB}_{2}, \mathrm{TiB}_{2}$, and their interface is represented in Fig. 3(c). A large number of defects can be observed inside the $\mathrm{MgB}_{2}$ grains close to the $\mathrm{MgB}_{2} /$ $\mathrm{TiB}_{2}$ interface. Inclusions $100-200 \mathrm{~nm}$ in size are found at the interface as well as at $\mathrm{MgB}_{2}$ grain boundaries. EDS analysis confirms that these inclusions are MgO, Fig. 3(f). Dark-field (DF) imaging was also used to examine the dislocations and the interface since crystal defects have stronger contrast under DF conditions. In Fig. 3(d), the DF image clearly confirms that the $\mathrm{MgB}_{2}$ grain contains a high density of defects. Detailed in-grain analysis was performed using HAADF imaging. Figure 3(e) shows a HAADF image of $\mathrm{MgB}_{2}$ grains with high defect density. Nano-size inclusions $\left(\sim 10-30 \mathrm{~nm}\right.$, white) dispersed both in and around $\mathrm{MgB}_{2}$ grains were observed. EDS analysis performed on randomly selected white inclusions confirmed that they were $\mathrm{TiB}_{2}$ (EDS spectrum of spot $\mathrm{E}$ (inclusion) in Fig. 3(f)). No Ti was detected by EDS in the other regions of $\mathrm{MgB}_{2}$ grains (EDS spectrum of spot $\mathrm{D}$ (matrix) in Fig. 3(f)). STEM-EDS analysis was applied across inclusion E, and beyond the $\mathrm{TiB}_{2} / \mathrm{MgB}_{2}$ interface the intensity of the $\mathrm{Ti}$ signal quickly dropped to zero, indicating that $\mathrm{Ti}$ did not dissolve into the $\mathrm{MgB}_{2}$ lattice. These nano-size $\mathrm{TiB}_{2}$ inclusions can also contribute to the high defect density observed in $\mathrm{MgB}_{2}$ grains in Fig. 3(c,d).

In the $\mathrm{NbB}_{2}$-added sample HTP-Nb-01 (HT below the peritectic), three phases are visible in the BSE images of Figs 4(a) and 5(b): $\mathrm{MgB}_{2}$ (majority phase, dark grey), $\mathrm{MgO}$ (minority phase, light grey) and $\mathrm{NbB}_{2}$ (minority phase, white). In Fig. 4(b), based on fractured secondary electron (SE) imaging by 'through the lens' (TTL) detection, $\mathrm{NbB}_{2}$ particles are observed outside the $\mathrm{MgB}_{2}$ grains. These particles are small $(\sim 300-500 \mathrm{~nm})$, well connected with the $\mathrm{MgB}_{2}$ grains, and dispersed throughout the bulks.

Further analysis was performed on a TEM thin foil sectioned from HTP-Nb-01. Both BF (Fig. 4(c)) and DF images (Inset of Fig. 4(c)) show nano-size inclusions $(\sim 300 \mathrm{~nm})$ embedded in the $\mathrm{MgB}_{2}$ grain boundaries. Moreover, a large number of defects can be observed inside the $\mathrm{MgB}_{2}$ grains around these inclusions, while the other $\mathrm{MgB}_{2}$ grains have fewer intragranular defects. The EDS results in Fig. 4(e) confirm that these inclusions are $\mathrm{NbB}_{2}$. HAADF imaging performed on $\mathrm{MgB}_{2}$ grains with high density of defects is presented in Figs 4(d) and 5(e). Nano-size inclusions $(\sim 10-50 \mathrm{~nm}$, white) were found inside these grains and high strain fields were observed around them. EDS analysis was applied on these distinct inclusions and several randomly selected spots in the matrix; those for spot $\mathrm{C}$ (matrix) and spot $\mathrm{D}$ (inclusion) are presented in Fig. 4(f). These EDS results confirm that these white inclusions were $\mathrm{NbB}_{2}$. A STEM-EDS line scan was applied across inclusion $\mathrm{D}$. The intensity of 

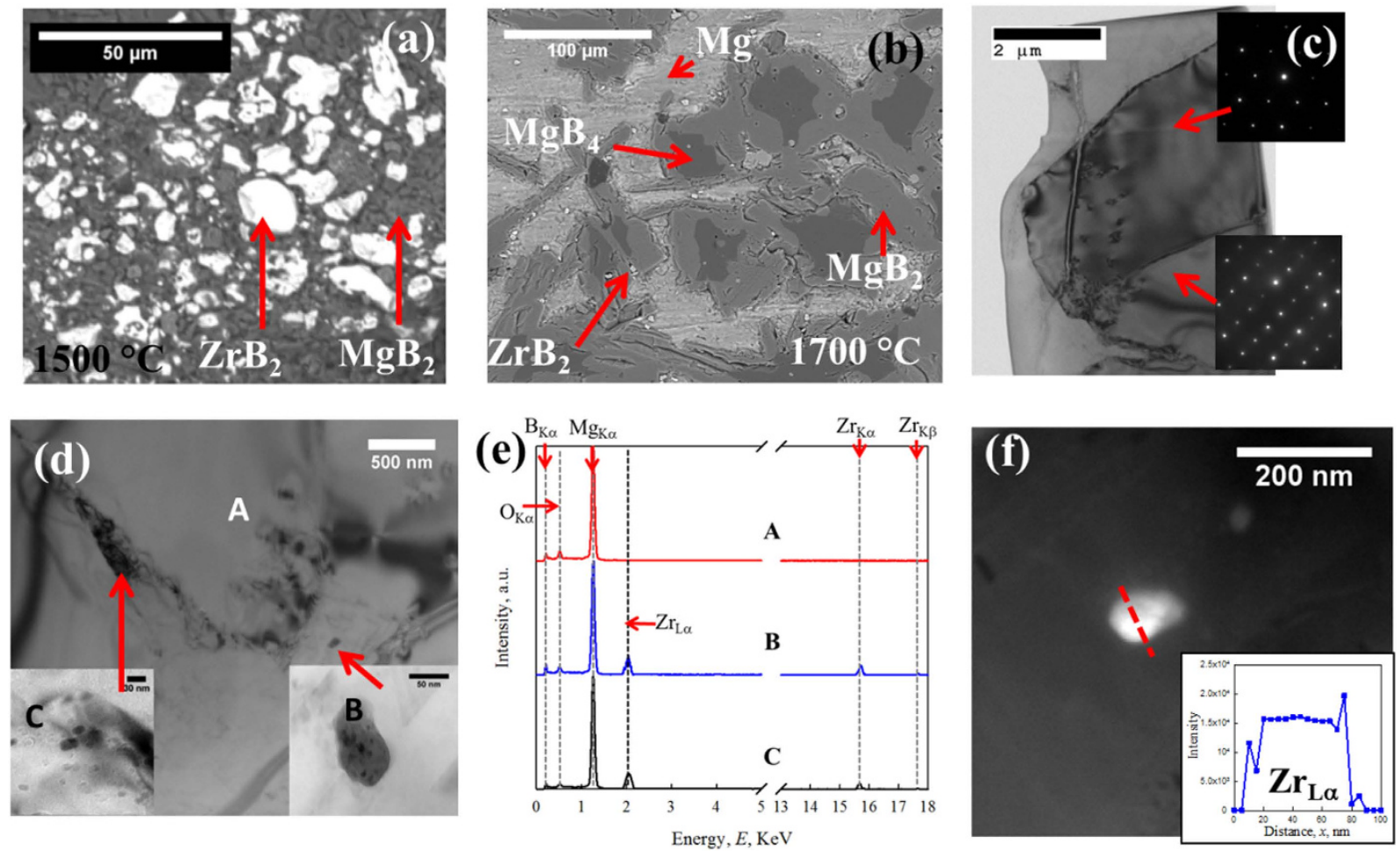

Figure 2. (a) BSE image of HTP-Zr-01; (b) BSE image of HTP-Zr-02; (c) BF TEM image of HTP-Zr-02 (Microstructures of the undoped bulk can be found in ${ }^{6,18,19}$ ). Insets are $\mathrm{SAD}$ of two distinct $\mathrm{MgB}_{2}$ grains; (d) nano-size inclusions observed close to/at $\mathrm{MgB}_{2}$ grain boundaries; (e) EDS spectra of spot A, B and C; (f) HAADF image of a nano-size inclusion close to $\mathrm{MgB}_{2}$ grain boundaries. Inset is the intensity of $\mathrm{Zr}_{\mathrm{L} \alpha}$ from STEM-EDS scanning across the inclusion (red dash line).

$\mathrm{Nb}$ signals abruptly decreased from $\sim 10^{4}$ to 0 across the $\mathrm{NbB}_{2} / \mathrm{MgB}_{2}$ interface and no $\mathrm{Nb}$ was detected in other regions of the $\mathrm{MgB}_{2}$ grains.

The microstructure of HTP-DY (HT above the peritectic) was investigated by BSE in Fig. 5(a). Five phases are visible: $\mathrm{MgB}_{2}$ (majority phase, dark grey), $\mathrm{Mg}$ (main phase, grey), $\mathrm{MgB}_{4}$ (minority phase, black), $\mathrm{MgO}$ (minority phase, light grey) and Dy-containing inclusions (minority phase, white). These Dy- containing inclusions ( $\mathrm{DyB}_{4}$ according to XRD results) with a size of $\sim 100 \mathrm{~nm}$ were dispersed throughout the bulk. Bright-field TEM examination revealed a number of impurity phases in the form of $\sim 10-50 \mathrm{~nm}$ inclusions inside the $\mathrm{MgB}_{2}$ grains in Fig. 5(b). A low density of large inclusions (over $100 \mathrm{~nm}$ ) was also observed (Fig. 5(c)). HAADF imaging (Fig. 5(c)) showed that these nano-size inclusions had a higher average atomic weight. EDS indicates that these inclusions contained Dy and B suggesting they are the previously XRD-identified $\mathrm{DyB}_{4}$. STEM-EDS analysis was applied across inclusion B (the red dashed line in Fig. 5(c)) and the result is shown in Fig. 5(e). No Dy was detected outside the inclusion.

Influence of $\mathrm{MB}_{2}$ and $\mathrm{Dy}_{2} \mathrm{O}_{3}$ doping on superconducting properties - Magnetic Results. The superconducting transition temperature $T_{c}$ and the distribution of $T_{c}$ of all samples were extracted by magnetization measurements, Fig. 6 . The onset $T_{c}$ s and the full-width half maximum (FWHM) of all samples are listed in Table 2. The undoped sample HTP-01 shows a very sharp superconducting transition with $T_{c}$ of $39.5 \mathrm{~K}$ and a FWHM of $\sim 0.4 \mathrm{~K}$. Below we describe the results for the doped samples.

ZrB ${ }_{2}$ Doping. In the $\mathrm{ZrB}_{2}$ doped samples, the onset $T_{c} \mathrm{~s}$ is $\sim 39.2 \mathrm{~K}$ in $\mathrm{HTP}-\mathrm{Zr}-01$ and $~ 39.4 \mathrm{~K}$ in $\mathrm{HTP}-\mathrm{Zr}-02$, respectively. The unchanged $T_{c}$ s suggest that a portion of these $\mathrm{ZrB}_{2}$ doped samples was unaffected with a $T_{c}$ equal to that of the undoped sample. Figures $6(\mathrm{a}, \mathrm{b})$, show very broad transitions and bi-modal peak in the $T_{c}$ distribution. This effect became more severe in HTP-Zr-02 indicating the presence of regions with various $T_{c} s$.

$\mathrm{TiB}_{2}$ Doping. Similarly, in the $\mathrm{TiB}_{2}$ doped samples, the onset $T_{c}$ s were unchanged, while their FWHMs were increased to $\sim 0.5 \mathrm{~K}$ in HTP-Ti-01 and $\sim 2.8 \mathrm{~K}$ in HTP-Ti-02, respectively.

$\mathrm{NbB}_{2}$ Doping. The $\mathrm{NbB}_{2}$ doped sample HTP-Nb-01 has an onset $T_{c}$ of $39.8 \mathrm{~K}$ and a FWHM of $\sim 1.0 \mathrm{~K}$.

Dy ${ }_{2} \mathrm{O}_{3}$ Doping. The $\mathrm{Dy}_{2} \mathrm{O}_{3}$ doped sample HTP-DY has an onset $T_{c}$ of $39.2 \mathrm{~K}$ and a FWHM of $\sim 0.5 \mathrm{~K}$.

The results for each of the $\mathrm{MB}_{2}$ samples was similar-after $\mathrm{MB}_{2}$ doping, the onset $T_{c}$ s were relatively unaffected, however their transition widths were significantly enhanced. We interpret this effect in terms of the presence of nanoscale $\mathrm{MB}_{2}$ (where $\mathrm{M}=\mathrm{Zr}$, Nb, or Ti) second phases which produce locally distorted regions separated by 

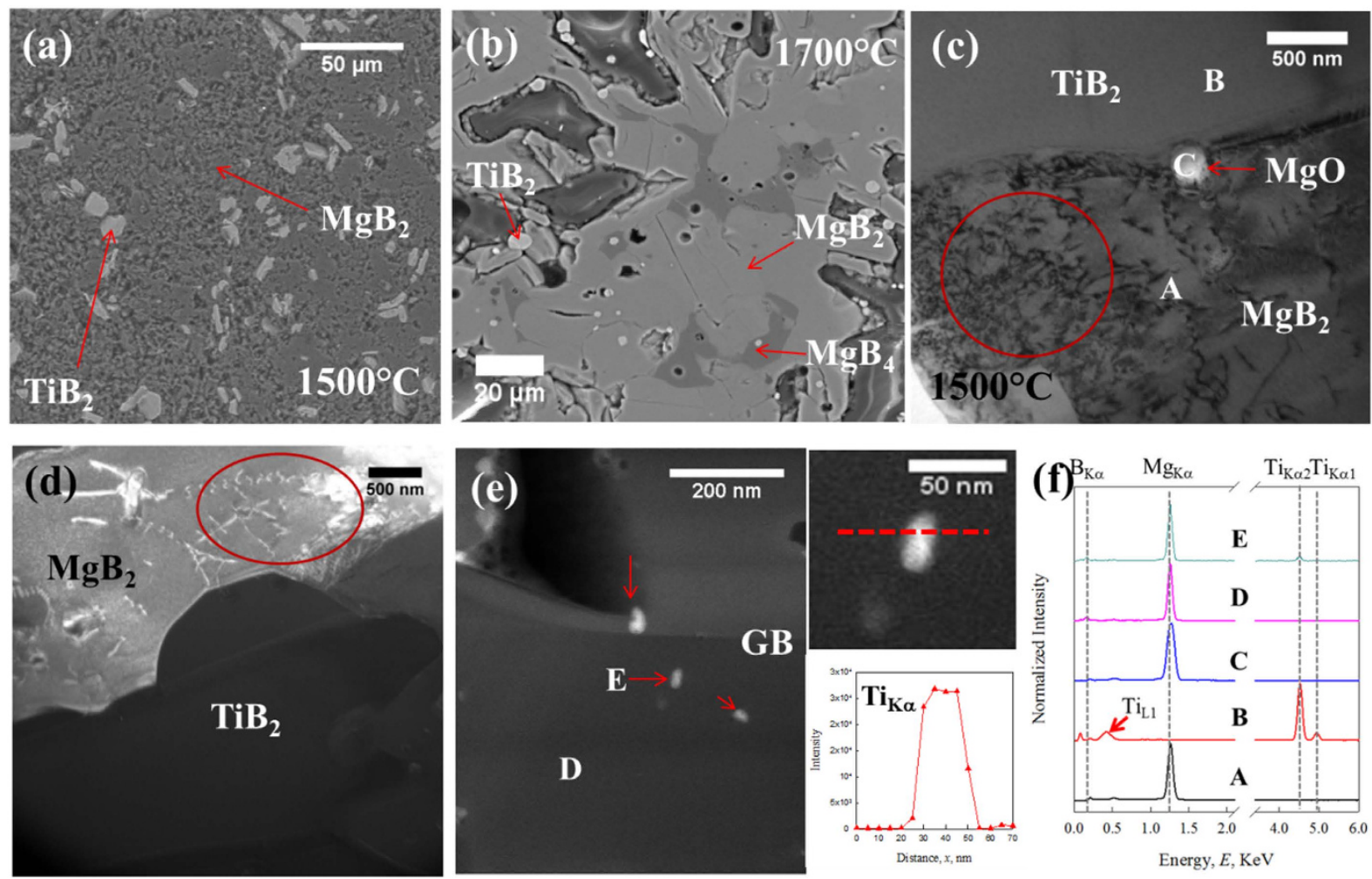

Figure 3. (a) BSE image of HTP-Ti-01; (b) BSE image of HTP-Ti-02; (c) BF TEM image of HTP-Ti-01. Large amount of crystal defects in $\mathrm{MgB}_{2}$ grain close to $\mathrm{MgB}_{2} / \mathrm{TiB}_{2}$ interface; (d) DF TEM image of ingrain crystal defects in $\mathrm{MgB}_{2}$ grain close to $\mathrm{TiB}_{2}$; (e) HAADF image of $\mathrm{MgB}_{2}$ grains with high defect density and STEM-EDS scanning across one of the nano-inclusions (red dash line). Inset is the intensity of $\mathrm{Ti}_{\mathrm{K \alpha}}$; (f) EDS spectra of spot A-E from $(\mathbf{c}, \mathbf{e})$.

large regions of unaffected $\mathrm{MgB}_{2}$, leading to broadened $T_{c}$ distributions with a wide $T_{c}$ variation ranging from $39 \mathrm{~K}$ to low values. Since these $\mathrm{MB}_{2}$ additives are isomorphous to $\mathrm{MgB}_{2}$ and their lattice parameters are close to those of $\mathrm{MgB}_{2}$, the localized distortion is probably due to the coherent strain generated around the $\mathrm{MB}_{2}$ inclusions. However, in HTP-DY both the onset $T_{c}$ and FWHM did not change by adding $\mathrm{Dy}_{2} \mathrm{O}_{3}$, which is consistent with Chen's observation ${ }^{17}$. The lattice parameters and crystal structures of $\mathrm{Dy}_{2} \mathrm{O}_{3}$ (cubic with space group Ia-3) ${ }^{20}$ and $\mathrm{DyB}_{4}$ (tetragonal with space group $\mathrm{P} 4 / \mathrm{mbm}$ ) ${ }^{21}$ are very different from $\mathrm{MgB}_{2}$ (hexagonal with space group P6/ $\mathrm{mmm})^{22}$, therefore it is unlikely that the Dy-contained inclusions in HTP-DY can generate coherent strain in the $\mathrm{MgB}_{2}$ grains.

As indicated above the $\mathrm{MB}_{2}$ dopants were mostly found as distinct impurity inclusions that only influenced the surrounding $\mathrm{MgB}_{2}$ grains through the $\mathrm{MgB}_{2} / \mathrm{MB}_{2}$ interfaces. Increasing the concentration of $\mathrm{MB}_{2}$ inclusions produced more "affected zones" leading to a wider $T_{c}$ distribution, Fig. 6(b). The behaviors of $\mathrm{MB}_{2}$ doped samples are quite different from those of C-doped $\mathrm{MgB}_{2}$ bulks ${ }^{6}$. After doping with 6.2 at.\% C Susner et al. ${ }^{6}$ observed a significant decrease in the onset $T_{c}$, from $39.5 \mathrm{~K}$ to $\sim 24 \mathrm{~K}$, while the FWHM changed from $0.65 \mathrm{~K}$ to $1.4 \mathrm{~K}^{6}$. Since C is known to be a substitutional defect, if homogeneous $\mathrm{C}$ doping is achieved, the onset $T_{c}$ and the lattice parameter $a$ will decrease simultaneously with increasing $\mathrm{C}$ doping levels ${ }^{6}$. Under $\mathrm{MB}_{2}$ doping, it seems that $\mathrm{Zr}$, Ti and $\mathrm{Nb}$ did not substitute for $\mathrm{Mg}$ or form homogeneous solid solutions with $\mathrm{MgB}_{2}$, even under $1700^{\circ} \mathrm{C}$ and $10 \mathrm{MPa}$. However, the properties of the host lattices in the vicinities of these dopants were indeed affected and their $T_{c} s$ were clearly altered, possibly due to local compositional changes caused either by $\mathrm{Mg}$ diffusion into $\mathrm{MB}_{2}$ particles or by local strain. Both of these possibilities could cause $T_{c}$ reduction, comparable to the effect of $\mathrm{Al}$ doping in $\mathrm{MgB}_{2}{ }^{23-25}$. Based on the results in the previous section, the affected vicinities probably had thicknesses similar to or smaller than $5 \mathrm{~nm}$-the resolution of STEM-EDS line scans used in this study.

The $T$ dependencies of the upper critical fields $B_{c 2}$ of all the samples are presented in Fig. $6(\mathrm{c})$. The $B_{c 2} \mathrm{~s}$ at $20 \mathrm{~K}$ linearly extrapolated from Fig. 6(c) are listed in Table 2 . It is clear that $B_{c 2}$ was increased by $\mathrm{MB}_{2}$ doping, but not by $\mathrm{Dy}_{2} \mathrm{O}_{3}$ doping. It is important to note, however, that since these $\mathrm{MB}_{2}$ doped samples were not homogeneous (as evidenced by the microstructure and the $T_{c}$ distribution), the $B_{c 2}$ values represent the properties of only a small fraction of the bulk samples. In other words, some "affected zones" inside these doped bulks have higher $B_{c 2}$ s than those in the unaffected $\mathrm{MgB}_{2}$, therefore their measured $B_{c 2}$ was enhanced. The observed high defect densities in the $\mathrm{MgB}_{2}$ grains, which increase electron scattering and reduce the electron mean free path, are likely responsible for the $B_{c 2}$ enhancement. These regions are at the edge of the grains, and can therefore act as connected percolative paths. In the $\mathrm{Dy}_{2} \mathrm{O}_{3}$ doped sample, although nano-size inclusions were observed inside the $\mathrm{MgB}_{2}$ grains, $B_{c 2}$ did not change. This observation together with the absence of changes in the lattice parameters, and lack of change 

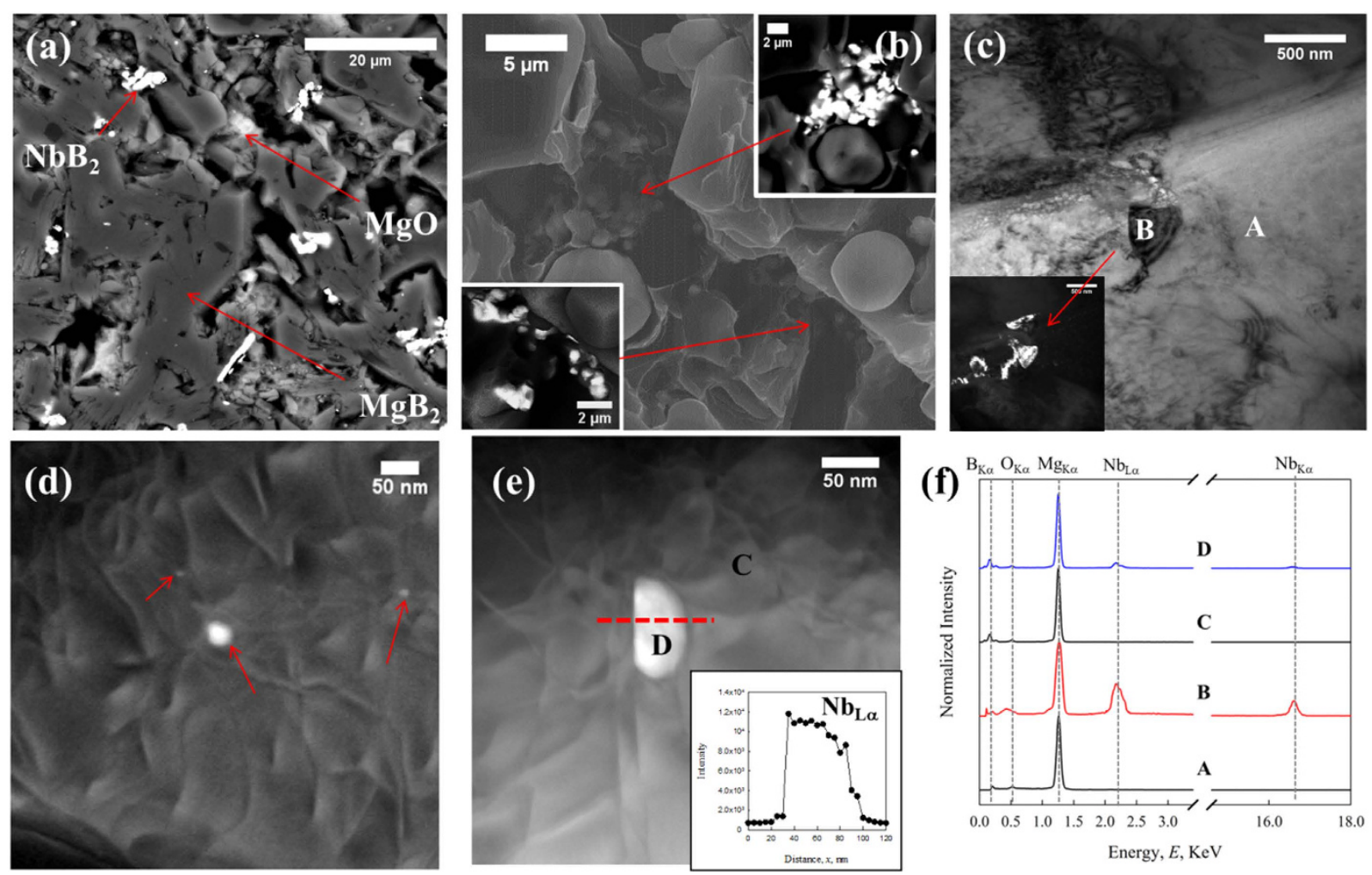

Figure 4. (a) BSE image of HTP-Nb-01; (b) fractured SE images, insets are BSE image of the fractured area; (c) BF TEM image of HTP-Nb-01 contained $\mathrm{NbB}_{2}$ inclusions. Inset is the DF TEM image of $\mathrm{NbB}_{2}$ inclusions; (d) HAADF image of $\mathrm{MgB}_{2}$ grains with high density of defects; (e) STEM-EDS scanning across one of the nanoinclusions (red dash line). Inset is the intensity of $\mathrm{Nb}_{\mathrm{L} \alpha} ;(\mathbf{f})$ EDS spectra of spot A-D.

in the $T_{c}$ and FWHM suggested that $\mathrm{Dy}_{2} \mathrm{O}_{3}$, unlike the metal diboride additions, did not cause a band of defect structure at the boundary of the $\mathrm{MgB}_{2}$ grain.

The magnetic critical current density $J_{c m}$ s and flux pinning behaviors of selected samples were calculated based on Bean's critical state model:

$$
J_{c m}=\frac{2 \Delta M}{b(1-b / 3 a)}
$$

where $\Delta M$ is the width of the hysteresis loop at a given field $B, a$ and $b$ are the edge lengths of the sample orthogonal to $\mathrm{B}(a>b)$. The results at $15 \mathrm{~K}$ are shown in Fig. 7. The $J_{c m}$ s for most of the field range were either not changed, or even reduced after $\mathrm{MB}_{2}$ doping; for HTP-DY, its $J_{c m}$ was slightly increased at all measured fields. A "tail" in $J_{c m}(B)$ can be observed in all $\mathrm{MB}_{2}$ doped samples, Fig. 7 (a). Based on the microstructural evidence and results of $B_{c 2}$ and $T_{c}$, this "tail" in $J_{c m}$ of the $\mathrm{MB}_{2}$ doped samples is probably caused by regions in the samples with different $B_{c 2}$ s. However these regions were too small to have significant influence on the overall $J_{c}\left(>100 \mathrm{~A} / \mathrm{cm}^{2}\right)$. The irreversibility field, $B_{i r}$, defined as the point where flux pinning vanishes, is often taken as the field at which $J_{c}(B)=100 \mathrm{~A} / \mathrm{cm}^{2}$. The results for these samples are given in Table 2; no increase in $B_{i r r}$ is seen, and in some cases there is a decrease. This definition of $B_{i r r}$ does not capture the high field and super-low- $J_{c}$ "tail" observed in Fig. 7(a).

$\mathrm{MgB}_{2}$ is primarily a grain boundary pinner, and thus the starting place to describe its pinning is the Kramer function (although deviations are seen). In order to perform such analysis, a Kramer field is needed. A Kramer plot, $J_{c}^{0.5} B^{0.25}$ versus $B$, is shown in Fig. 7(b). The Kramer fields, $B_{k}$, taken at the cross-intercepts of linear fittings (Black dash lines in Fig. 7(b)) are listed in Table 2. The values of $B_{k}$, similarly to those of $B_{i r r}$, were stable or slightly reduced after $\mathrm{MB}_{2}$ doping, unlike the values of $B_{c 2}$ which increased with doping. This effect is due to several factors: (1) the higher $B_{c 2}$ region was apparently small, presumably restricted to the defected zones near the grain boundaries, these regions will not substantially influence the measured $B_{k}$; (2) the $B_{k}$ is also affected by the sample connectivity, possibly reduced with second phases present. For samples with $\mathrm{Dy}_{2} \mathrm{O}_{3}$ additions, $B_{c 2}, B_{i r r}$, and $B_{k}$ were not affected.

Figure 7 (c) is a plot of bulk pinning force density $\left(F_{p}=J_{c m} \times B\right)$ vs $B$; the maximum values, $F_{p m a x}$, are listed in Table 2. Compared to the literature values, the $F_{p, \max }$ of these HTP processed bulks is quite small. Spark-plasma sintering ${ }^{26}$ gives a $J_{c}$ at $2 \mathrm{~T}$ and $15 \mathrm{~K}$ of about $10^{5} \mathrm{~A} / \mathrm{cm}^{2}$, while our values here are closer to $2 \times 10^{3} \mathrm{~A} / \mathrm{cm}^{2}$. The $F_{p, \max }$ of the undoped sample HTP-01 is only $\sim 0.095 \mathrm{GN} / \mathrm{m}^{3}$ while according to Susner ${ }^{6}$ at $15 \mathrm{~K}$ the $F_{p, \max }$ of an undoped $\mathrm{MgB}_{2}$ wire was about $2 \mathrm{GN} / \mathrm{m}^{3}$. The main reason for the difference is that the $\mathrm{MgB}_{2}$ grains in these HTP 

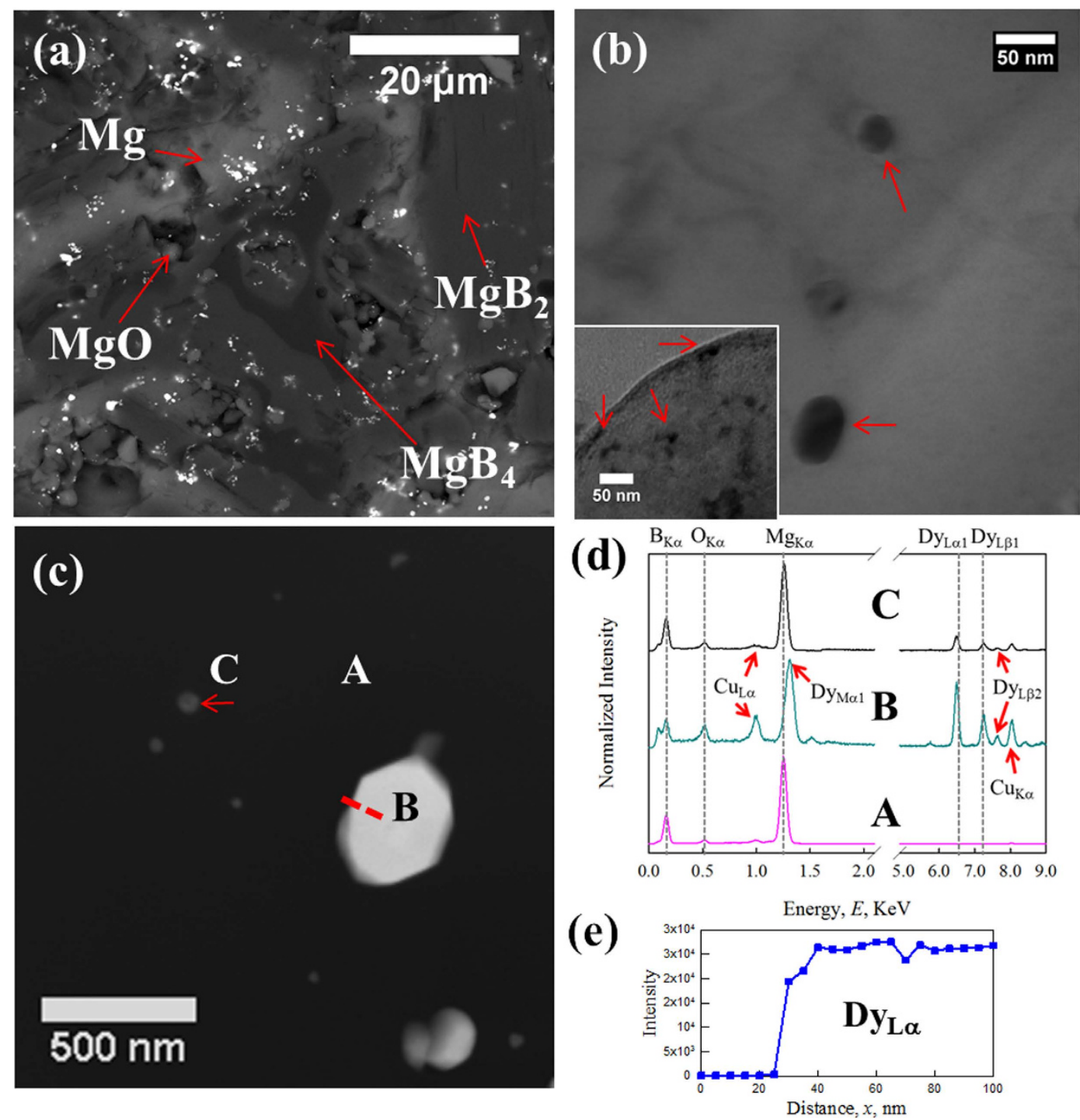

Figure 5. (a) BSE image of HTP-DY, four different phases $\left(\mathrm{MgB}_{2}, \mathrm{MgB}_{4}, \mathrm{Mg}\right.$ and $\left.\mathrm{MgO}\right)$ are labeled; (b) $\mathrm{BF}$ TEM image of nano-size inclusions (10-50 nm) are found inside $\mathrm{MgB}_{2}$ grains; (c) HAADF image of one $\mathrm{MgB}_{2}$ grain, white precipitates are Dy-contained; (d) EDS spectra of spot A-C in (c); (e) the intensity of $\mathrm{Dy}_{\mathrm{L} \alpha}$ from STEM-EDS scanning (red dash line in $(\mathbf{c})$ ).

bulks $(>5 \mu \mathrm{m})$ are much larger than those in the traditional synthesized samples (typically $30-500 \mathrm{~nm})$. Other factors could also contribute to this difference in $F_{p, \text { max }}$, including some reduction of connectivity by small amounts of $\mathrm{MgO}$. However, as $J_{c} \propto 1$ /grain size, and the grain size in our samples is roughly 50 times larger than the highest performing $\mathrm{MgB}_{2}$, the grain size effect is expected to be dominant. Among all samples, the highest value of $F_{p, \max }\left(\sim 0.135 \mathrm{GN} / \mathrm{m}^{3}\right)$ was observed in HTP-DY. The normalized bulk pinning force density $f_{p}=F_{p} / F_{p, \max }$ is plotted against normalized magnetic field $b=B / B_{k}$ in Fig. $7(\mathrm{~d})$. The functions of grain boundary (GB) pinning from the Dew-Hughes model ${ }^{27}, f_{p} \propto b^{1 / 2}(1-b)^{2}$, are also plotted for comparison. Although the undoped sample HTP-01 followed GB pinning function quite well, all doped samples show a deviation from the standard function. The peaks of $f_{p}$ in the doped samples were shifted from the value of $b=0.2$ (the peak position of the GB pinning) to lower values. For example, the peaks in HTP-Zr-01, HTP-Ti-01, HTP-Nb-01 and HTP-DY were $0.12,0.13,0.11$ and 0.10 , respectively. This observation which was also reported by Matsushita et al. ${ }^{28}$ in C doped $\mathrm{MgB}_{2}$ bulk samples can be explained by two possibilities: (1) These doped samples might contain a set of local $B_{k}$ s instead of one distinct value (just like the $B_{c 2}$ in the $\mathrm{MB}_{2}$ doped samples), which can lead to an artificial error in the estimation of the peak positions; while the variation in $B_{k}$ of the undoped sample was small, thus the undoped sample followed the GB pinning function. (2) The deviation from $b_{\text {peak }}=0.2$ might be caused by the operation of other pinning mechanisms (e.g., normal volume pinning in which $f_{p}$ maximizes at $b \rightarrow 0.0^{27}$ ) in association with the GB pinning. As noted above, we clearly see a distribution of Dy-based second phases, consistent with ${ }^{17}$. Also present were modest levels of $\mathrm{MgO}$, known both to act as a pinner and in some cases reduce connectivity ${ }^{29}$. However, any small $\mathrm{MgO}$ effects should be present in all samples. The parameter $a$ of the flux line lattice (FLL) is given by $a=1.07\left(\Phi_{0} / B\right)^{1 / 2}$, where $\Phi_{0}$ is the quantum of magnetic flux $\left(\Phi_{0}=2.07 \times 10^{-15} \mathrm{~Wb}\right)$. Based 
(a)

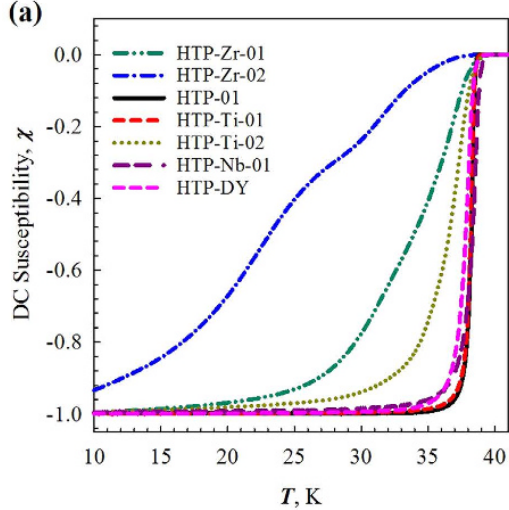

(b) 1.2

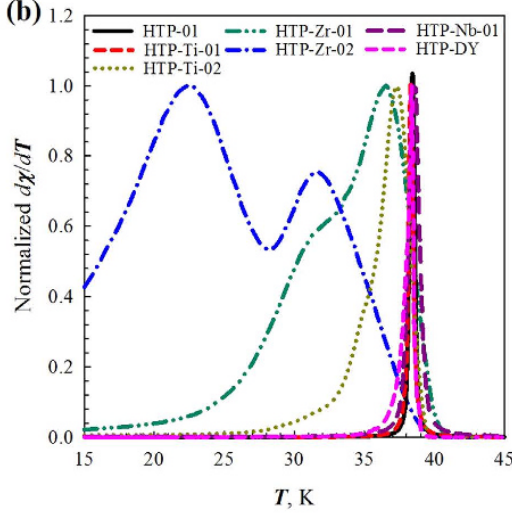

(c)

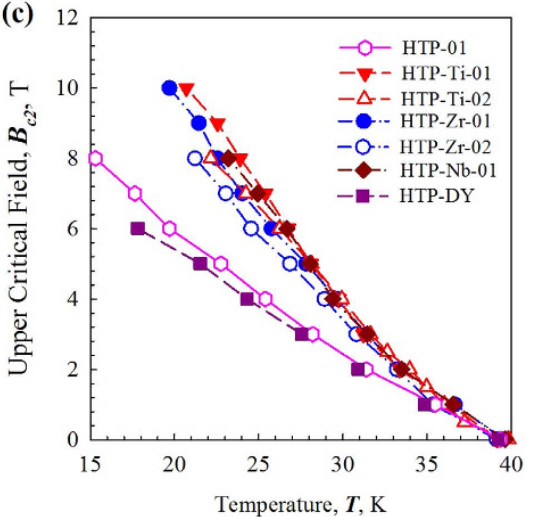

Figure 6. (a) DC susceptibility $\chi$ vs $T$ at $0.01 \mathrm{~T}$; (b) the $T_{c}$ distribution - $\mathrm{d} \chi / \mathrm{d} T$ vs $T$; and (c) the temperature dependent $B_{c 2}(T)$ curves of the all $\mathrm{MgB}_{2}$ samples.

\begin{tabular}{|l|c|c|c|c|c|c|}
\hline Sample & Onset $\boldsymbol{T}_{\boldsymbol{c}}(\mathbf{K})$ & FWHM of $\boldsymbol{T}_{\boldsymbol{c}}(\mathbf{K})$ & $\boldsymbol{B}_{c 2}$ at $\mathbf{2 0 ~ K}(\mathbf{T})$ & $\boldsymbol{B}_{\boldsymbol{k}}$ at 15 K (T) & $\boldsymbol{B}_{i r r}$ at $\mathbf{1 5} \mathbf{K}(\mathbf{T})$ & $\boldsymbol{F}_{p \max }\left(\mathrm{GN} / \mathbf{m}^{\mathbf{3}}\right)$ \\
\hline HTP-01 & 39.5 & 0.4 & 5.8 & 3.58 & 3.24 & 0.095 \\
\hline HTP-Zr-01 & 39.2 & $\sim 10$ & 10 & 2.47 & 2.66 & 0.063 \\
\hline HTP-Zr-02 & 39.4 & $>15$ & 8 & - & - & - \\
\hline HTP-Ti-01 & 39.5 & 0.5 & 10 & 3.27 & 3.15 & 0.079 \\
\hline HTP-Ti-02 & 39.6 & 2.8 & 8.2 & - & - & - \\
\hline HTP-Nb-01 & 39.8 & 1.0 & 9 & 2.88 & 2.56 & 0.091 \\
\hline HTP-DY & 39.2 & 0.5 & 5.6 & 3.51 & 3.30 & 0.134 \\
\hline
\end{tabular}

Table 2. Comparison of the superconducting properties amount the $\mathrm{MgB}_{2}$ samples.

on this expression, the values of $a$ vary from $\sim 50 \mathrm{~nm}$ at $1 \mathrm{~T}$ to $\sim 20 \mathrm{~nm}$ at $6 \mathrm{~T}$. By definition, the size of the volume pins needs to be larger than $a$. Considering the fact that these doped samples contained intragrain inclusions some of which were bigger than the FLL parameter $a$ at every measured field, it appears that volume pinning contributed to these shifts in $F_{p, \max }$.

In summary, after adding $\mathrm{MB}_{2}$, the $B_{c 2}$ of $\mathrm{MgB}_{2} \mathrm{HTP}$ bulks increased, the $T_{c}$ distributions were broadened, but $T_{c}, B_{k}$ and $J_{c}$ remained unchanged (or slightly reduced). Considering the microstructural evidence, this observation can be explained as follows: only very small regions (possible $\leq 5 \mathrm{~nm}$ in thickness) around dopant particles of the $\mathrm{MgB}_{2}$ grains are influenced by doping, leaving the majority of $\mathrm{MgB}_{2}$ unaffected. To the contrary, the $\mathrm{Dy}_{2} \mathrm{O}_{3}$ doping did not change the $T_{c}, T_{c}$ distribution and $B_{c 2}$, instead it increased the $J_{c}$ and flux pinning apparently associated with the nano-size precipitates in $\mathrm{MgB}_{2}$ grains.

\section{Conclusion}

In this work we have used our HTP method for synthesizing doped $\mathrm{MgB}_{2}$ bulks at high temperatures (up to $1700^{\circ} \mathrm{C}$ ) and at pressure $(10 \mathrm{MPa})$ to explore solubility limits of dopant species in $\mathrm{MgB}_{2}$, maximize diffusion, and (alternatively) attempt to form dense, nanoscale secondary phases during the sample synthesis. We explored both metal diborides $\left(\mathrm{MB}_{2}\right.$, where $\mathrm{M}=\mathrm{Zr}$, Ti and $\left.\mathrm{Nb}\right)$ for attempted $\mathrm{Mg}$ site substitution and $\mathrm{Dy}_{2} \mathrm{O}_{3}$ for nanoscale intragrain precipitate formation. Using the HTP process we conclusively show that the large increases in $B_{c 2}$ with metal diboride additions are due to a highly defected band within the grain, rather than substitution or inclusion within the grain, or grain boundary effects. High defect densities observed in $\mathrm{MgB}_{2}$ grains around/with these $\mathrm{MB}_{2}$ inclusions, cause electron scattering and therefore contribute to the $B_{c 2}$ enhancement and $T_{c}$ distribution broadening. On the other hand, these regions ( $\leq 5 \mathrm{~nm}$ in thickness) were not large enough to significantly influence the high field $J_{c}, B_{i r}$, or $B_{k}$. This observation explains the frequently observed increases seen for $B_{c 2}$ in materials with no accompanying increase in transport current. We also confirm the previously observed but sparsely distributed intragrain precipitates formed with $\mathrm{Dy}_{2} \mathrm{O}_{3}$ additions. $\mathrm{Dy}_{2} \mathrm{O}_{3}$ additions not change the lattice parameters, $T_{c}, T_{c}$ distribution and $B_{c 2}$ of $\mathrm{MgB}_{2}$, but increased the $J_{c}$ and flux pinning by forming an array of nano-size precipitates in $\mathrm{MgB}_{2}$ grains.

\section{Methods}

Sample Synthesis. Three sets of $\mathrm{MgB}_{2}$ bulks with various $\mathrm{MB}_{2}(\mathrm{M}=\mathrm{Zr}$, Ti and $\mathrm{Nb})$ dopants were fabricated at high temperatures and under pressure. This HTP process ${ }^{18,19}$ based on the reactive liquid Mg infiltration $(\mathrm{Mg}-\mathrm{RLI})$ method $^{30}$. Three metal borides with a structure isomorphous to $\mathrm{MgB}_{2}(\mathrm{P} 6 / \mathrm{mmm})$ were selected as vectors for Mg-site substitution: $\mathrm{ZrB}_{2}$ (99.5\%, Alfa Aesar), $\mathrm{TiB}_{2}$ (99.5\%, Alfa Aesar) and $\mathrm{NbB}_{2}$ (99.5\%, Alfa Aesar). As the $\mathrm{Dy}_{2} \mathrm{O}_{3}$ additive, $\mathrm{Dy}_{2} \mathrm{O}_{3}(>99.9 \%,<100 \mathrm{~nm}$ particle size, ALDRICH) was used. Amorphous $\mathrm{B}$ powder (50-100 nm in size) manufactured by Specialty Metals Inc. ${ }^{31,32}$ was hand mixed with the dopant powder and high energy ball milled for $15 \mathrm{~min}$ in an Ar atmosphere. These dopants and B powder mixtures were then pressed into 

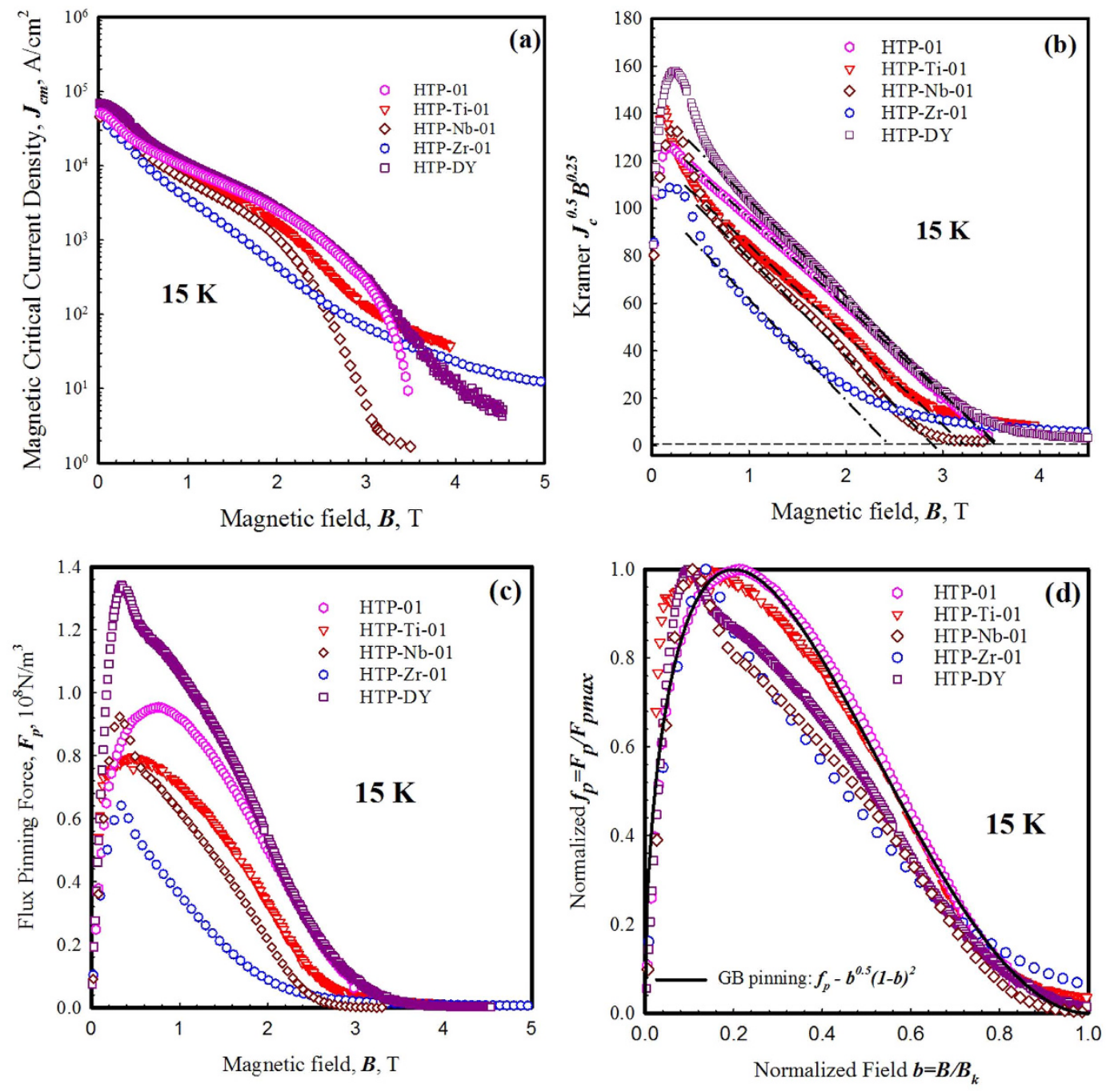

Figure 7. (a) Magnetic critical current density $J_{c m}$ vs $T$; (b) Kramer plot $J_{c}^{0.5} B^{0.25}$ vs $B$; (c) The flux pinning density $F_{p}$ vs $B$; and (d) Normalized flux pinning behavior $f_{p}$ vs $b$ of the undoped sample HTP-01 and the doped samples HTP-Zr-01, HTP-Ti-01, HTP-Nb-01 and HTP-DY at $15 \mathrm{~K}$.

$\sim 8 \mathrm{~mm}$ tall by $\sim 13 \mathrm{~mm}$ diameter pellets and placed in an $\mathrm{MgO}$ crucible. Mg turnings ( 4 mesh, $99.98 \%$, Alfa Aesar) were packed on top. The Mg:B ratio in the crucible was about 1:1 to avoid possible $\mathrm{Mg}$ deficiencies during heat treatment. This crucible was capped and placed inside the HTP autoclave (see also ${ }^{18,19}$ ). All samples were heat treated at $10 \mathrm{MPa}$ in an $\mathrm{Ar}$ atmosphere. Two heat treatment routes were used: (1) heating up to $1500^{\circ} \mathrm{C}$ and soaking for $30 \mathrm{~min}$; (2) heating up to $1700^{\circ} \mathrm{C}$ and soaking for $20 \mathrm{~min}$. A slow cooling rate of $5^{\circ} \mathrm{C} / \mathrm{min}$ was used in both HT routes to maintain thermal equilibrium. The first route was designed to limit the temperature to just below the peritectic decomposition point of the reaction, thus preventing decomposition while maximizing the diffusion of the dopant species. The second route was designed to allow the reaction to occur on the temperature upswing, and hence to form $\mathrm{MgB}_{2}$ directly from $\mathrm{MgB}_{4}$ and $\mathrm{Mg}^{+}$dopant species on cooling:

$$
\begin{aligned}
& T<T_{p} \quad M g+2 B \quad \Rightarrow M g B_{2} \\
& T>T_{p} \quad 2 M g B_{2} \quad \Rightarrow M g B_{4}+M g \\
& \text { Cooling } \mathrm{MgB}_{4}+\mathrm{Mg} \Rightarrow 2 \mathrm{MgB}_{2}
\end{aligned}
$$

where $T_{p}$ is the peritectic temperature $\left(\sim 1500^{\circ} \mathrm{C}\right.$ in our experiments).

Measurements. A Rigaku SmartLab X-ray diffractometer (using $\mathrm{Cu} \mathrm{K} \alpha$ of $1.5406 \AA$ ) was used for structural characterization and the scanning angle $2 \theta$ ranged from $20^{\circ}$ to $80^{\circ}$. A FEI/Philips Sirion scanning electron microscope (SEM) with a field-emission source and a through-the-lens (TTL) detector was used for microstructural imaging. An FEI Helios 600 dual beam focused ion beam instrument (FIB) with an Omniprobe micromanipulation tool was used to prepare TEM thin foils. The TEM imaging was performed on a FEI/Philips CM-200T transmission electron microscope (TEM) with a silicon drift detector (SDD) and energy-dispersive X-ray spectroscopy function (EDS). The high-angle annular dark-field imaging (HAADF) and EDS line scans with a resolution of 
$\sim 5 \mathrm{~nm}$ were performed on a Tecnai F20 system field emission $200 \mathrm{kV}$ scanning transmission electron microscope (STEM) with an X-TWIN lens and high brightness field emission electron gun (FEG).

The magnetic properties were measured by using a Quantum Design Model 6000 PPMS with $4.2 \mathrm{~K}<T<300 \mathrm{~K}$ and $-10 \mathrm{~T}<B<10 \mathrm{~T}$. The superconducting critical transition temperature $T_{c}$ and $T_{c}$ distribution were determined by DC magnetic susceptibility methods. The $T_{c}$ was defined as the onset of superconductivity from the normal state at $10 \mathrm{mT}$ and the $T_{c}$ distribution was expressed in terms of $\mathrm{d} \chi / \mathrm{d} T$, where $\chi$ is the DC susceptibility. $M$ - $T$ curves were taken at $1 \mathrm{~T}$ intervals from $0-14 \mathrm{~T}$. The upper critical field, $B_{c 2}$, was determined by the highest temperature point where the $M-T$ curves deviated from $M=0$ at each given field. The irreversibility field, $B_{i r r}$, was taken as the field at which $J_{c}(B)=100 \mathrm{~A} / \mathrm{cm}^{2}$. The Kramer field, $B_{k}$, was taken as the point where $J_{c}^{0.5} B^{0.25}$ extrapolated to zero on a Kramer plot (Fig. 7(b)), and the bulk pinning force density, $F_{p}$, was calculated from $F_{p}=J_{c} B$, where $J_{c}$ was extracted from the magnetization results at various temperatures.

\section{References}

1. Dou, S. X. et al. Mechanism of enhancement in electromagnetic properties of $\mathrm{MgB}_{2}$ by Nano SiC Doping. Phys. Rev. Lett. 98,097002 (2007).

2. Susner, M. A. et al. Influence of $\mathrm{Mg} / \mathrm{B}$ ratio and $\mathrm{SiC}$ doping on microstructure and high field transport $J_{c}$ in $\mathrm{MgB}_{2}$ strands. Physica C 456, 180-187 (2007).

3. Susner, M. A. et al. Enhanced critical fields and superconducting properties of pre-doped B powder-type $\mathrm{MgB}_{2}$ strands. Supercond. Sci. Technol. 24, 012001 (2011).

4. Bohnenstiehl, S. D. et al. Carbon doping of $\mathrm{MgB}_{2}$ by toluene and malic-acid-in-toluene. Physica C 471, 108-111 (2011).

5. Yang, Y. et al. Influence of strand design, boron type and carbon doping method on the transport properties of powder-in-tube $\mathrm{MgB}_{2-\mathrm{x}} \mathrm{C}_{\mathrm{x}}$ strands. IEEE Tran. Appl. Supercond. 22, 2 (2012).

6. Susner, M. A. et al. Homogeneous carbon doping of magnesium diboride by high-temperature high-pressure synthesis. Appl. Phys. Lett. 104, 162603 (2014).

7. Gurevich, A. et al. Very high upper critical fields in $\mathrm{MgB}_{2}$ produced by selective tuning of impurity scattering. Supercond. Sci. Technol. 17, 278-286 (2004).

8. Collings, E. W., Sumption, M. D., Bhatia, M., Susner, M. A. \& Bohnenstiehl, S. D. Prospects for improving the intrinsic and extrinsic properties of magnesium diboride superconducting strands Supercond. Sci. Technol. 21, 103001 (2008).

9. Slusky, J. S. et al. Loss of superconductivity with the addition of $\mathrm{Al}$ to $\mathrm{MgB}_{2}$ and a structural transition in $\mathrm{Mg}_{1-\mathrm{x}} \mathrm{Al}_{\mathrm{x}} \mathrm{B}_{2}$. Nature 410, 343-345 (2001)

10. Xiang, J. Y. et al. Superconducting properties and c-axis superstructure of $\mathrm{Mg}_{1-\mathrm{x}} \mathrm{Al}_{\mathrm{x}} \mathrm{B}_{2}$. Phys. Rev. B 65, 214536 (2002).

11. Feng, Y. et al. Improvement of critical current density in $\mathrm{MgB}_{2}$ superconductors by $\mathrm{Zr}$ doping at ambient pressure. Appl. Phys. Lett. 79, 3983 (2001)

12. Feng, Y. et al. Enhanced flux pinning in Zr-doped $\mathrm{MgB}_{2}$ bulk superconductors prepared at ambient pressure. J. Appl. Phys. 92, 2614 (2002).

13. Bhatia, M., Sumption, M. D., Collings, E. W. \& Dregia, S. Increases in the irreversibility field and the upper critical field of bulk $\mathrm{MgB}_{2}$ by $\mathrm{ZrB}_{2}$ addition. Appl. Phys. Lett. 87, 042505 (2005).

14. Zhang, X. P. et al. Improved critical current densities in $\mathrm{MgB}_{2}$ tapes with $\mathrm{ZrB}_{2}$ doping. Appl. Phys. Lett. 89, 132510 (2006).

15. Susner, M. A., Sumption, M. D., Takase, A. \& Collings, E. W. Evidence for Zr site-substitution for Mg in PLD-deposited $\mathrm{MgB}_{2}$ thin films. Supercond. Sci. Technol. 27, 075009 (2014).

16. Susner, M., Influences of crystalline anisotropy, porosity, and connectivity on the critical current densities of superconducting magnesium diboride bulks, wires, and thin Films, Ph.D. dissertation, The Ohio State University (2012).

17. Chen, S. K., Wei, M. \& MacManus-Driscoll, J. L. Strong pinning enhancement in $\mathrm{MgB}_{2}$ using very small $\mathrm{Dy}_{2} \mathrm{O}_{3}$ additions. Appl. Phys. Lett. 88, 192512 (2006).

18. Bohnenstiehl, S. D. et al. Experimental determination of the peritectic transition temperature of $\mathrm{MgB}_{2}$ in the $\mathrm{Mg}-\mathrm{B}$ phase diagram. Thermochim. Acta 576, 27-35 (2014).

19. Bohnenstiehl, S. D. Thermal analysis, phase equilibria, and superconducting properties in $\mathrm{MgB}_{2}$ and carbon-doped $\mathrm{MgB}_{2}, \mathrm{Ph} . \mathrm{D}$. dissertation, The Ohio State University (2012).

20. Curzon, A. E. \& Chlebek, H. G. The observation of face centred cubic Gd, Tb, Dy, Ho, Er and Tm in the form of thin films and their oxidation. J. Phys. F 3, 1-5 (1973).

21. Yin, Z. P. \& Pickett, W. E. Rare-earth-boron bonding and $4 \mathrm{f}$ state trends in $\mathrm{RB}_{4}$ tetraborides. Phys. Rev. B 77, 035135 (2008).

22. Nagamatsu, J., Nakagawa, N., Muranaka, T., Zenitani, Y. \& Akimitsu, J. Superconductivity at $39 \mathrm{~K}$ in magnesium diboride. Nature, 410, 63 (2001).

23. Kortus, J., Dolgov, O. V. \& Kremer, R. K. Band filling and interband scattering effects in $\mathrm{MgB}_{2}$ : carbon versus aluminum doping. Phys. Rev. Lett. 94, 027002 (2005).

24. Cooley, L. D. et al. Inversion of two-band superconductivity at the critical electron doping of (Mg,Al)B. Phys. Rev. Lett. 95, 267002 (2005).

25. Zambano, A. J., Moodenbaugh, A. R. \& Cooley, L. D. Effects of different reactions on composition homogeneity and superconducting properties of Al-doped $\mathrm{MgB}_{2}$. Supercond. Sci. Technol. 18, 1411-1420 (2005).

26. Aldica, G. et al. "The influence of heating rate on superconducting characteristics of $\mathrm{MgB}_{2}$ obtained by spark plasma sintering technique". Physica C 19, 184-189 (2015).

27. Dew-Hughes, D. Flux pinning mechanisms in type II superconductors. Philos. Mag. 30, 2, 293-305 (1974).

28. Matsushita, T. Flux Pinning in Superconductors 2nd edn, Ch. 9.2, 384-386 (Springer, 2014).

29. Kovac, P. et al. The role of $\mathrm{MgO}$ content in ex situ $\mathrm{MgB}_{2}$ wires, Rapid Communication. Supercond. Sci. Technol. 17, L41-L46 (2004).

30. Giunchi, G., Ceresara, S., Ripamonti, G., Chiarelli, S. \& Spadoni, M. $\mathrm{MgB}_{2}$ reactive sintering from the elements. IEEE Trans. Appl. Superconduct. 13, 3060 (2003).

31. Marzik, J. V. et al. Plasma synthesized doped B powders for $\mathrm{MgB}_{2}$ superconductors. Physica C 423, 3-4 83-88 (2005).

32. Kim, J. H. et al. Comparative study of mono- and multi-filament $\mathrm{MgB}_{2}$ wires with different boron powders and malic acid addition. Supercond. Sci. Technol. 23, 075014 (2010).

\section{Acknowledgements}

This work was supported by the NIH, National Institute of Biomedical Imaging and Bioengineering, under R01EB018363.

\section{Author Contributions}

M.D.S., E.W.C. and Y.Y. developed the topical area and thrust of this study. Y.Y. initiated this study, completed the experiments, and wrote the manuscript. M.D.S. and E.W.C. reviewed the results and the manuscript. 


\section{Additional Information}

Competing financial interests: The authors declare no competing financial interests.

How to cite this article: Yang, Y. et al. Influence of Metal Diboride and $\mathrm{Dy}_{2} \mathrm{O}_{3}$ Additions on Microstructure and Properties of $\mathrm{MgB}_{2}$ Fabricated at High Temperatures and under Pressure. Sci. Rep. 6, 29306; doi: 10.1038/ srep29306 (2016).

(c) (i) This work is licensed under a Creative Commons Attribution 4.0 International License. The images or other third party material in this article are included in the article's Creative Commons license, unless indicated otherwise in the credit line; if the material is not included under the Creative Commons license, users will need to obtain permission from the license holder to reproduce the material. To view a copy of this license, visit http://creativecommons.org/licenses/by/4.0/ 